\title{
Knowledge, Attitude and Practice of Laboratory Staff on Computer: Role in Scaling up Xpert MTB/RIF in Nigeria
}

\author{
Nwadike P. ${ }^{1}$, Gidado M. ${ }^{1}$, Sani U. ${ }^{1}$, Nwokoye N. ${ }^{3}$, Elom E. ${ }^{2}$, Onazi J. ${ }^{1}$, Ajiboye P. ${ }^{1}$, Iwakun M. ${ }^{4}$ \\ ${ }^{1}$ KNCV Nigeria / Challenge TB Project, 4th Floor- Block B, Independence Avenue Central Business District- Abuja, Nigeria \\ ${ }^{2}$ National Tuberculosis \& Leprosy Control Program, Federal Ministry of Health, Abuja, Nigeria \\ ${ }^{3}$ National TB Reference Laboratory, Microbiology Division, Nigerian Institute of Medical Research, Lagos, Nigeria \\ ${ }^{4}$ Institute of Human Virology (IHVN), Abuja, Nigeria
}

\section{Email address:}

Peter.nwadike@kncvtbc.org (Nwadike P.), mustapha.gidado@kncvtbc.org (Gidado M.), useni.sani@kncvtbc.org (Sani U.), nkirunwokoye@ymail.com (Nwokoye N.), elomek@yahoo.com (Elom E.), jumoke.onazi@kncvtbc.org (Onazi J.), prisca.ajiboye@kncvtbc.org (Ajiboye P.), miwakun@ihvnigeria.org (Iwakun M.)

\section{To cite this article:}

Nwadike P., Gidado M., Sani U., Nwokoye N., Elom E., Onazi J., Ajiboye P., Iwakun M.. Knowledge, Attitude and Practice of Laboratory Staff on Computer: Role in Scaling up Xpert MTB/RIF in Nigeria. Science Journal of Public Health. Special Issue: Who Is Afraid of the Microbes. Vol. 3, No. 5-1, 2015, pp. 40-44. doi: 10.11648/j.sjph.s.2015030501.18

\begin{abstract}
Information, Communication Technology (ICT) has become the order of the day. Globally, there is increasing quest for use of ICT in various spheres of life. The Health care sector is not left out: Computer based diagnosis is the hope of fast and accurate diagnostic process. GeneXpert machines for rapid diagnosis of Tuberculosis (TB) and drug resistant tuberculosis (DR-TB), work with GeneXpert (GX) software and computer programs. This study was carried out to assess Knowledge, Attitude and Practice of Laboratory staff on computer with the view to unraveling its role in scaling up Xpert MTB/Rif in Nigeria. The survey was done using a structured, closed-ended questionnaire administered to laboratory staff operating GeneXpert machine, who participated in the study. A total of 76 GeneXpert machine operators $(56.7 \%)$ out of 134 laboratory staff trained from 31 Xpert sites in Nigeria were interviewed. These included 49 Laboratory Scientists, 15 laboratory technicians and 12 other laboratory staff that operate the machine. Majority, 55 (72.4\%) of the respondents had good knowledge of computer; 43 (78.2\%), $4(7.3 \%)$ and $8(14.5 \%)$ of these were laboratory scientists, technicians and other laboratory staff respectively. Good computer knowledge was highest among scientists and lowest among technicians. These differences were statistically significant $(\mathrm{df}=1 \mathrm{P}$ $<0.01)$. Age, gender, owning a personal computer and formal computer training significantly influenced computing knowledge. Most Xpert MTB/RIF users $45(64.5 \%)$ had positive attitude towards computing and this was significantly influenced by respondent's age and formal computer training. Only $38(50 \%)$ had good computing practice; this was significantly associated with owning a personal computer $(\mathrm{P}<0.01)$ and formal computer training. The major computer operation challenges observed among the laboratory staff included; Xpert calibration; completion of electronic recording tool and software operations like importing of assay definition file; plunger maintenance; generating system and error log reports as well as archiving/retrieving of tests. Introduction of basic computer training module into the Xpert training curriculum, strict adherence to SOP, continuous supportive supervision and mentorship training are recommended in Nigeria to boost efficiency of laboratory staff.
\end{abstract}

Keywords: Computer, Knowledge, Attitude, Practice, Laboratory, Xpert MTB/RIF

\section{Introduction}

Globally, there is increasing quest for use of ICT in various spheres of life. The Health care sector is not left out $[1,2]$. Computer based diagnosis is the hope of fast and accurate diagnostic process $[3,4]$. Xpert MTB/RIF is a novel rapid tuberculosis (TB) molecular diagnostic tool $[5,6]$ which makes use of GeneXpert machine installed with computer programs and software [7]. The Xpert MTB/RIF is a cartridge-based, automated diagnostic test that can identify the aetiologic agent of tuberculosis, Mycobacterium tuberculosis (MTB) DNA and resistance to rifampicin (RIF) by nucleic acid amplification technique (NAAT) [8, 9, 10] with a turn-around time of approximately 2 hours.

Quick and effective diagnosis and treatment of patients with drug-resistant tuberculosis (TB), particularly multidrug-resistant (MDR) and extensively drug-resistant 
(XDR) tuberculosis, drastically reduces mortality, nosocomial outbreaks, and resistance to additional anti-tuberculosis drugs $[11,12]$. It is worthy to note that, MDR and XDR tuberculosis can be effectively treated if properly identified [13]. The Xpert MTB/RIF comes in handy with its very short turn-around time as a life-saving tool. However, since the machine works with GeneXpert software [7] and computer program, it becomes necessary to evaluate the computer knowledge, attitude and practice of laboratory staff involved in operation of the machine.

This study was therefore carried out to assess knowledge, attitude and practice of Laboratory staff on computer with the view to unraveling its role in scaling up Xpert MTB/Rif in the Nigeria.

\section{Methodology}

\subsection{Study Area}

The 31 GeneXpert sites managed by KNCV Nigeria/ TBCARE I project across Nigeria were used in this study.

\subsection{Duration of Study}

The study was carried out between January and March 2014.

\subsection{Study Subjects}

Laboratory workers who were trained by KNCV Nigeria / TB CARE I project on Xpert machine usage were used for this study. Those recruited had at least 3 months on the job experience with Xpert machine in the respective sites/ facilities.

A total of 76 Participants out of over 134 laboratory staff trained were randomly selected proportionate to the number of GeneXpert users in the various facilities. The subjects/respondents included 49 Medical Laboratory Scientists, 15 technologists and 12 other laboratory workers who operate the GeneXpert machines in the various facilities.

\subsection{Study Instrument}

A pre-tested, structured, closed-ended interviewee / interviewer-administered questionnaire was used. The questionnaires were proportionally shared among the 31 GeneXpert sites in Nigeria. Seventy-six (76) respondents out of 134 laboratory staff who were trained on Xpert machine usage completed their questionnaires.

\subsection{Study Design and Indices}

A cross sectional quantitative study of the KNCV/TB CARE I supported GeneXpert laboratories was carried out and used to determine the impact of the Knowledge, Attitude and Practice of Laboratory staff on computer in scaling up Xpert MTB/RIF in Nigeria. The factors affecting Knowledge, Attitude and Practice of Laboratory staff on computer: its role in scaling up Xpert MTB/RIF in Nigeria was also assessed.

Computer knowledge was defined as a basic understanding of computer concepts and computer based Xpert operations. It involves knowledge of hard and soft ware, including the use of basic computer applications like computer network and file management. Using the methods of Mohammed et al., [2] in their study on knowledge and utilization of computer among health workers for analysis; those who scored greater than $80 \%, 60 \%$ to $79 \%$, and less than $60 \%$ of knowledge questions were classified as having adequate, fair and inadequate computer knowledge respectively.

Practice of computer was defined as ability to use basic skills of computer in file management, storage, retrieval, analysis and presentation of data from the Xpert machine and other personal computers. Using the same method above, those respondents scoring $60 \%, 50 \%$ to $59 \%$ and less than $50 \%$ of questions on practice of computer were considered as having adequate, fair and inadequate computer practice abilities respectively.

Data was presented using tables and charts. Simple percentage was used for the descriptive analysis of the data. Associations between participant's characteristics, profession, knowledge, attitude and practice of computer and corresponding roles in scale up of Xpert MTB/RIF usage were analyzed using $\chi^{2}$ test.

\section{Results}

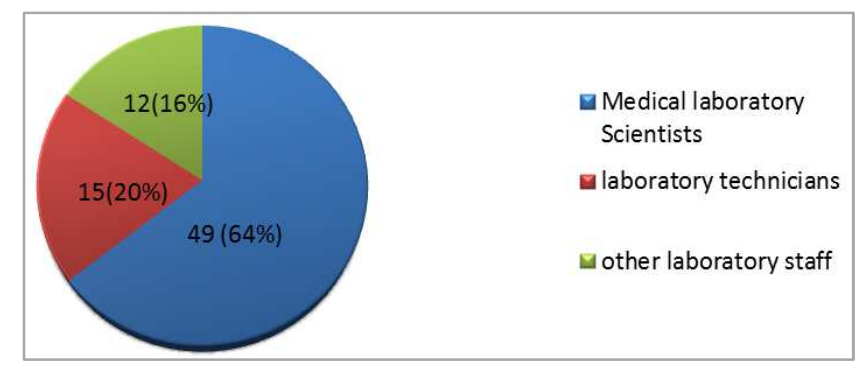

Figure 1. Proportion of respondents by profession.

Table 1. Factors affecting knowledge and practice of computer among Xpert users.

\begin{tabular}{|c|c|c|c|c|c|c|c|c|}
\hline \multirow{3}{*}{ Factors } & & \multirow{3}{*}{ NP } & \multicolumn{6}{|c|}{ Frequency (Number (\%) } \\
\hline & & & \multicolumn{3}{|c|}{ Computer Knowledge } & \multicolumn{3}{|c|}{ Computer Practice } \\
\hline & & & Adequate & Fair & Low & Adequate & Fair & Low \\
\hline \multirow{3}{*}{ Profession } & MLS & 49 & $43(87.8)$ & $6(12.2)$ & $0(0.0)$ & $28(57.2)$ & $3(6.1)$ & $18(36.7)$ \\
\hline & Tech & 15 & $4(26.7)$ & $7(46.7)$ & $4(26.7)$ & $4(26.7)$ & $2(13.3)$ & $9(60)$ \\
\hline & OLW & 12 & $8(66.7)$ & $2(16.7)$ & $2(16.7)$ & $6(50)$ & $3(25)$ & $3(25)$ \\
\hline \multirow{2}{*}{ Sex } & Male & 44 & $35(79.6)$ & $7(15.9)$ & $2(4.5)$ & $22(50)$ & $4(9.1)$ & $18(40.9)$ \\
\hline & Female & 32 & $20(62.5)$ & $8(25)$ & $4(12.5)$ & $16(50)$ & $4(12.5)$ & $12(37.5)$ \\
\hline \multirow{2}{*}{ Age } & a. $15-25$ & 15 & $9(60)$ & $5(33.3)$ & $1(6.7)$ & $3(20)$ & $3(20)$ & $9(60)$ \\
\hline & b. $26-35$ & 35 & $28(80)$ & $4(11.4)$ & $3(8.6)$ & $24(68.6)$ & $3(8.6)$ & $8(22.9)$ \\
\hline
\end{tabular}




\begin{tabular}{|c|c|c|c|c|c|c|c|c|}
\hline \multirow{3}{*}{ Factors } & & \multirow{3}{*}{ NP } & \multicolumn{6}{|c|}{ Frequency (Number (\%) } \\
\hline & & & \multicolumn{3}{|c|}{ Computer Knowledge } & \multicolumn{3}{|c|}{ Computer Practice } \\
\hline & & & Adequate & Fair & Low & Adequate & Fair & Low \\
\hline \multirow{6}{*}{ Level of education } & c. $36-45$ & 23 & $17(73.9)$ & $5(21.7)$ & $1(4.4)$ & $10(43.5)$ & $2(8.7)$ & $11(47.8)$ \\
\hline & d. $>45$ & 3 & $1(33.3)$ & $1(33.3)$ & $1(33.3)$ & $1(33.3)$ & $0(0.0)$ & $2(66.7)$ \\
\hline & Secondary & 6 & $4(66.6)$ & $1(16.7)$ & $1(16.7)$ & $1(16.7)$ & $1(16.7)$ & $4(66.6)$ \\
\hline & Diploma & 35 & $21(60)$ & $9(25.7)$ & $5(14.3)$ & $10(28.6)$ & $5(14.3)$ & $20(57.1)$ \\
\hline & First degree & 27 & $23(85.2)$ & $4(14.8)$ & $0(0.0)$ & $21(77.8)$ & $1(3.7)$ & $5(18.5)$ \\
\hline & postgraduate & 8 & $7(87.5)$ & $1(12.5)$ & $0(0.0)$ & $6(75)$ & $1(12.5)$ & $1(12.5)$ \\
\hline \multirow{2}{*}{ Ownership of PC } & YES & & $38(69.1)$ & $4(26.7)$ & $0(0.0)$ & $33(86.8)$ & $5(62.5)$ & $4(13.3)$ \\
\hline & NO & & $17(30.9)$ & $11(73.3)$ & $6(100)$ & $5(13.2)$ & $3(37.5)$ & $26(86.7)$ \\
\hline \multirow{2}{*}{$\begin{array}{l}\text { Formal computer } \\
\text { training }\end{array}$} & YES & & $40(72.7)$ & $6(40)$ & $1(16.7)$ & $33(86.8)$ & $5(62.5)$ & $7(23.3)$ \\
\hline & NO & & $15(27.3)$ & $9(60)$ & $5(83.3)$ & $5(13.2)$ & $3(37.5)$ & $23(76.7)$ \\
\hline
\end{tabular}

Key for Tables 1-3:

MLS: Medical Laboratory Scientist

TECH: Technicians

OLW: Other Laboratory Workers

PC: Personal Computer

NP: Number of Partcipants

Table 2. Factors affecting Attitude to Computer among Xpert users.

\begin{tabular}{|c|c|c|c|c|c|}
\hline \multirow{3}{*}{ Factors } & & \multirow{3}{*}{ No of Participants } & \multicolumn{3}{|c|}{ Frequency (Number (\%)) } \\
\hline & & & \multicolumn{3}{|l|}{ Attitude } \\
\hline & & & Adequate & Fair & Low \\
\hline \multirow{3}{*}{ Profession } & MLS & 49 & $33(67.3)$ & $9(18.4)$ & $7(14.3)$ \\
\hline & Tech & 15 & $5(33.3)$ & $7(46.7)$ & $3(20)$ \\
\hline & OLW & 12 & $7(58.3)$ & $5(41.7)$ & $0(0.0)$ \\
\hline \multirow{2}{*}{ Sex } & Male & 44 & $27(61.4)$ & $9(20.5)$ & $8(18.2)$ \\
\hline & Female & 32 & $18(56.3)$ & $12(37.5)$ & $2(6.3)$ \\
\hline \multirow{4}{*}{ age } & a. $15-25$ & 15 & $5(33.3)$ & $6(40)$ & $4(26.7)$ \\
\hline & b. $26-35$ & 35 & $28(80)$ & $6(17.1)$ & $1(2.9)$ \\
\hline & c. $36-45$ & 23 & $11(47.8)$ & $9(39.1)$ & $3(13.0)$ \\
\hline & d. $>45$ & 3 & $1(33.3)$ & $0(0.0)$ & $2(66.7)$ \\
\hline \multirow{4}{*}{ Education level } & Secondary & 6 & $2(33.3)$ & $2(33.3)$ & $2(33.3)$ \\
\hline & Diploma & 35 & $14(40)$ & $14(40)$ & $7(20)$ \\
\hline & First degree & 27 & $22(81.5)$ & $4(14.8)$ & $1(3.7)$ \\
\hline & postgraduate & 8 & $7(87.5)$ & $1(12.5)$ & $0(0.0)$ \\
\hline \multirow{2}{*}{ Ownership of PC } & YES & & $35(77.8)$ & $5(23.8)$ & $2(20)$ \\
\hline & NO & & $10(22.2)$ & $16(76.2)$ & $8(80)$ \\
\hline \multirow{2}{*}{ Formal computer training } & YES & & $38(84.4)$ & $5(23.8)$ & $2(20)$ \\
\hline & NO & & $7(15.6)$ & $16(76.2)$ & $8(80)$ \\
\hline
\end{tabular}

Table 3. Impact of Xpert users' Profession on effective operation and scale up of Xpert MTB/RIF in Nigeria.

\begin{tabular}{llll}
\hline \multirow{2}{*}{ Xpert operations } & \multicolumn{2}{l}{ Profession (Number (\%) } & \\
\cline { 2 - 4 } & MLS & TECH & OLW \\
\hline Plunger maintenance & $33(67.3)$ & $4(26.7)$ & $7(58.3)$ \\
Xpert calibration & $3(6.1)$ & $1(6.6)$ & $0(0.0)$ \\
Archiving test results & $25(51)$ & $2(13.3)$ & $4(33.3)$ \\
Generation of system log report, IQ report & $10(20.4)$ & $0(0.0)$ & $2(16.7)$ \\
Importation of assay definition file & $9(18.4)$ & $0(0.0)$ & $1(8.3)$ \\
Viewing and reading test Ct values & $12(24.5)$ & $1(6.7)$ & $3(25)$ \\
Computation of Xpert quarterly summary data tool & $28(57.1)$ & $3(20)$ & $6(50)$ \\
Familiarity with GeneXpert software & $49(100)$ & $12(80)$ & $10(83.3)$ \\
\hline
\end{tabular}


Table 4. Impact of Computing Knowledge and Practice on effective operation and scale up of Xpert MTB/RIF in Nigeria among Xpert users.

\begin{tabular}{|c|c|c|c|c|c|c|}
\hline \multirow{3}{*}{ Xpert operations } & \multicolumn{6}{|c|}{ Frequency (Number (\%)) } \\
\hline & \multicolumn{3}{|c|}{ Computer Knowledge } & \multicolumn{3}{|c|}{ Computer Practice } \\
\hline & Adequate & Fair & Low & Adequate & Fair & Low \\
\hline Plunger maintenance & $44(80)$ & $10(66.7)$ & $3(50)$ & $25(65.8)$ & $6(75)$ & $4(13.3)$ \\
\hline Xpert calibration & $4(7.2)$ & $1(6.7)$ & $0(0.0)$ & $4(10.5)$ & $1(12.5)$ & $0(0.0)$ \\
\hline Archiving test results & $31(56.4)$ & $5(33.3)$ & $0(0.0)$ & $25(65.8)$ & $4(50)$ & $2(6.7)$ \\
\hline Generation of system log report, IQ report & $13(23.6)$ & $6(40)$ & $1(16.7)$ & 28(73.6) & $2(25)$ & $3(10)$ \\
\hline Importation of assay definition file & $16(29.1)$ & $2(13.3)$ & $0(0.0)$ & $10(26.3)$ & $2(25)$ & $0(0.0)$ \\
\hline Viewing and reading test $\mathrm{Ct}$ values & $16(29.1)$ & $3(20)$ & $1(16.7)$ & $16(42.1)$ & $3(37.5)$ & $2(6.7)$ \\
\hline Computation of Xpert quarterly summary data tool & $37(62.3)$ & $6(40)$ & $0(0.0)$ & $30(78.9)$ & $4(50)$ & $3(10)$ \\
\hline Familiarity with GeneXpert software & $55(100)$ & $15(100)$ & $5(83.3)$ & $38(100)$ & $8(100)$ & $29(96.7)$ \\
\hline
\end{tabular}

Table 5. Impact of Xpert users' Attitude to Computer on effective operation and scale up of XpertMTB/RIF in Nigeria.

\begin{tabular}{llll}
\hline \multirow{2}{*}{ Ability to perform Xpert operations } & Attitude (Number (\%) & Fair & Low \\
\cline { 2 - 4 } & Adequate & $6(28.6)$ & $3(30)$ \\
\hline Plunger maintenance & $27(60)$ & $3(14.3)$ & $0(0.0)$ \\
Xpert calibration & $4(8.8)$ & $6(28.6)$ & $1(10)$ \\
Archiving test results & $27(60)$ & $4(19.0)$ & $1(10)$ \\
Generation of system log report, IQ report & $35(77.7)$ & $5(23.8)$ & $1(10)$ \\
Importation of assay definition file & $10(22.2)$ & $10(47.6)$ & $0(0.0)$ \\
Viewing and reading test Ct values & $17(37.8)$ & $13(61.9)$ & $3(30)$ \\
Computation of Xpert quarterly summary data tool & $37(82.2)$ & $20(95.2)$ & $9(90)$ \\
Familiarity with GeneXpert software & $43(95.6)$ & \\
\hline
\end{tabular}

\section{Discussions}

Generally, all the participants had some level of computer knowledge and practice though the levels varied from low, fair to adequate / good. Medical laboratory scientists showed significantly higher knowledge as well as positive attitude and practice of computer than technicians and other laboratory staff respectively (Table 1). Technicians on the other hand, had the lowest computing knowledge, and practice. This had a proportionate effect on their various abilities to effectively carry out Xpert operations (Tables 2 and 3) especially those involving software such as importing of assay definition file; plunger maintenance; generating system and error log reports and archiving/retrieving of tests. This is in agreement with postulations of Bello et al. [3] that improved computer knowledge would improve health care delivery. They opined that an information-proficient workforce that is computer literate and motivated to use the well-designed clinical systems would be necessary in a developing country such as Nigeria. In contrast, Zeka et al, [5] earlier opined that Xpert operation is less dependent on the user's skills, and routine staff with minimal training can use the test. This may be the reason why some operators with low computer knowledge were able to perform some of the operations without assistance while some with good knowledge were not able to do so. However, this study generally revealed significant better operations with better knowledge of computer.

The low knowledge and practice of computer patterns observed among the Technicians may have been as a result of lack of structured training and computer accessibility. Other authors $[2,14]$ in their respective studies had earlier revealed similar low patterns. In contrast, studies $[15,16]$ in different places reported higher patterns from their research. It was also observed that, lower number of females possessed personal computers than their male counterparts. This might be due to the fact that most Nigerian women who are mothers after office work engage in domestic activities, thereby having little or no time for computer practice unlike their male counterpart. Another reason could be that fewer females possess personal computers and this corroborates the findings of [2].

Gender, formal computer training and owing personal computer significantly influenced computing knowledge as well as practice $(\mathrm{P}<0.01)$. This was demonstrated among young and middle aged (26-45yrs), most of them having adequate computer knowledge, practice and right attitude. These are mostly working class staff who have access to computer system by virtue of their education or work. However, there was no significant difference in computing attitude with regards to gender and computer ownership (P > 0.01). In a similar study, [2] reported that sex, professional background and possession of own computer had significant statistical association with computer utilization but not significant with computer knowledge among health workers in Ethiopia. Ibrahim et al., [15] also had same opinion.

Age of respondents also significantly influenced knowledge, attitude and practice. This corroborates a study in India which reported that age has significant association with computer knowledge [14].

Computer training was an indicator that cut across knowledge, attitude and practice: it is however expected because training leads to knowledge and attitudinal changes. Mohammed et al., [2] noted that "innovation can be adopted after having knowledge about the innovation to be adopted". Similarly respondents who owned personal computers were expected to have more knowledge than those who did not.

The major computer related operation challenges observed among the laboratory staff included; Xpert calibration; correct completion of electronic recording tool and software operations; importing of assay definition file, plunger 
maintenance, generating system and error log reports as well as archiving/retrieving of tests. These challenges were noticed even among staff with basic computer knowledge and practice. Nonetheless, these challenges could be resolved towards a successful Xpert scale up through introduction of computer education among laboratory staff, continuous capacity building [17] and supervision. These interventions can help to institutionalize new cultures, structures and practices among the laboratory staff as opined by [17].

It is therefore necessary that on-going on-the-job training be put in place to ensure that Xpert operators understand and are able to undertake these operations. This will in addition enhance scale up of Xpert MTB/RIF in Nigeria.

\section{Conclusion}

The findings herein have revealed the need for introduction of basic computer training module into the GeneXpert training curriculum. Increasing accessibility to computers and delivering training on the use of computers for workers will increase the knowledge and utilization of computers [2]. Continuous support and mentorship training are recommended in Nigeria to boost efficiency of laboratory staff. These are in turn expected to enhance and maximize scale up of Xpert MTB/RIF in Nigeria thereby helping to reduce the TB-burden of the country.

\section{References}

[1] M. R. Myers, "Telemedicine: an emerging health care technology," Health Care Manag (Frederick), 2003; 22 (3):219-223.

[2] E. Mohammed, G. Andargie, S. Meseret and E. Girma, "Knowledge and utilization of computer among health workers in Addis Ababa hospitals, Ethiopia: computer literacy in the health sector," Biomed central Research Notes, 2013, vol. 6, Pp. 106, DOI: 10.1186/1756-0500-6-106.

[3] I. S. Bello, F. A. Arogundade, A. A. Sanusi, I. T. Ezeoma, E. A. Abioye-Kuteyi and A. Akinsola, "Knowledge and utilization of Information Technology among health care professionals and students in Ile-Ife, Nigeria: A Case Study of a University Teaching Hospital,” J. Med. Internet Res. 2004, vol. 6(4):e45), DOI: 10.2196

[4] F. Feliciani, "Medical care from space: Telemedicine," ESA Bull; 2003, vol. 114, Pp. 54-59.

[5] A. N. Zeka, S. Tasbakan and C. Cavusoglu, "Evaluation of the GeneXpert MTB/RIF Assay for Rapid Diagnosis of Tuberculosis and Detection of Rifampin Resistance in Pulmonary and Extrapulmonary Specimens. Journal of Clinical Microbiology, 2011, vol. 49(12): 4138-4141, DOI: 10.1128/JCM.05434-11.
[6] WHO, "Monitoring of Xpert MTB/RIF rollout," World Health Organisation; Geneva, 2013.

[7] Cepheid (2009). Cepheid Brochure: Xpert®MTB/RIF. Two-hour detection of MTB and resistance to rifampicin. Available:

http://www.cepheid.com/media/files/eu/brochures/XpertMTB Broch R9`EU.pd f. Accessed 21 ${ }^{\text {st }}$ July, 2014.

[8] P. M. Small and M., Pai, "Tuberculosis diagnosis - time for a game change" N. Engl. J. Med. 2010, vol. 363: 1070-1071.

[9] A. Van Rie, L. Page-Shipp, L. Scott, I. Sanne and W. Stevens, "Xpert ${ }^{\circledR}$ MTB/RIF for point-of-care diagnosis of TB in high-HIV burden, resource-limited countries: hype or hope?" Expert Rev. Mol. Diagn., 2010, vol. 10: 937-946.

[10] C. C. Boehme, C. C., et al. "Rapid molecular detection of tuberculosis and rifampin resistance" N. Engl. J. Med., 2010, vol. 363: 1005-1015.

[11] P. Farmer, J. Bayona, M. Becerra, J. Furin, C. Henry, H. Hiatt, J. Y. Kim, C. Mitnick, E. Nardell, and S. Shin, "The dilemma of MDR-TB in the global era," Int. J. Tuberc. Lung Dis., 1998. Vol. 2:869-876.

[12] C. D. Mitnick, S. S. Shin, K. J. Seung, M. L. Rich, S. S. Atwood, J. J. Furin, G. M. Fitzmaurice, F. A. Alcantara Viru, S. C. Appleton, J. N. Bayona, C. A. Bonilla, K. Chalco, S. Choi, M. F. Franke, H. S. Fraser, D. Guerra, R. M. Hurtado, D. Jazayeri, K. Joseph, K. Llaro, L. Mestanza, J. S. Mukherjee, M. Munoz, E. Palacios, E. Sanchez, A. Sloutsky, and M. C. Becerra, "Comprehensive treatment of extensively drug-resistant tuberculosis," N. Engl. J. Med. 2008, vol. 359:563-574.

[13] D. A. Moore, C. A. Evans, R. H. Gilman, L. Caviedes, J. Coronel, A. Vivar, E. Sanchez, Y. Pinedo, J. C. Saravia, C. Salazar, R. Oberhelman, M. G. Hollm-Delgado, D. LaChira, A. R. Escombe, and J. S. Friedland, "Microscopic-observation drug-susceptibility assay for the diagnosis of TB," N. Engl. J. Med. 2006, vol. 355:1539-1550.

[14] E. Raja, R. Mahal, V. Masih, "An exploratory study to assess the computer knowledge, attitude and skill among nurses in health care setting of a selected hospital, Ludhiana, Punjab, India," Online J Nurs Inform, 2004, vol.8:1304-1307.

[15] S, Ibrahim, A. Fatiu, A. Abubakr, "Knowledge and utilization of information technology among health care professionals and students," J Med Internet Res 2004, vol. 6:e45.

[16] F. Yaghmaie, R. Javasuriva and P. Rawstorne, "Computer experience and computer attitude," Stud Health Technol Inform, 1998, vol. 52:895-899.

[17] Dirk Rombout Essink, Sustainable Health Systems: the role of change agents in health system innovation, Uitgeverij BoxPress, 's Hertogenbosch, the Netherlands, 2012, Pp. 34. 